\title{
A geospatial model to determine the spatial cost-efficiency of anticoagulation drug therapy: Patients' perspective
}

\author{
Mikko Pyykönen, ${ }^{1}$ Aapeli Leminen, ${ }^{1}$ Juho Tynkkynen, ${ }^{2,3}$ Markku Tykkyläinen, ${ }^{1}$ \\ Tiina Laatikainen ${ }^{4-6}$ \\ ${ }^{1}$ Department of Geographical and Historical Studies, University of Eastern Finland, Joensuu; ${ }^{2}$ Faculty of \\ Medicine and Health Technology, Tampere University, Tampere; ${ }^{3}$ Department of Radiology, Kanta-Häme \\ Central Hospital, Hämeenlinna; ${ }^{4}$ Institute of Public Health and Clinical Nutrition, University of Eastern \\ Finland, Kuopio; ${ }^{5}$ Joint Municipal Authority for North Karelia Social and Health Services, Joensuu; \\ ${ }^{6}$ Department of Public Health Solutions, National Institute for Health and Welfare, Helsinki, Finland
}

\begin{abstract}
Most atrial fibrillation (AF) patients need anticoagulation management to reduce the risk of thromboembolic events and
\end{abstract}

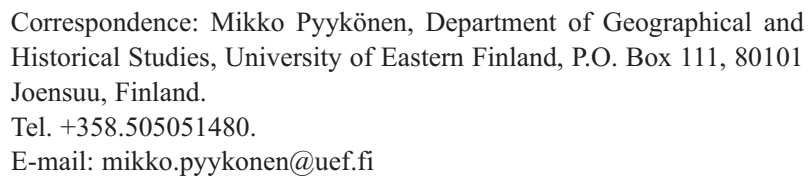

Key words: Geographical information systems; Atrial fibrillation; Least-cost therapy; Market areas; Network analysis.

Contributions: MP designed the study and MT conceptualised the theoretical framework. MP made the analyses and wrote the manuscript. MT, AL, TL wrote parts of the body text and contributed to the interpretation of the results. JT provided clinical expertise in treatment process definitions. All authors contributed to the critical revision of the manuscript and approved the final manuscript.

Conflict of interest: the authors declare no potential conflict of interest.

Funding: the Strategic Research Council at the Academy of Finland (decision number 312704) funded the final stage of this research. The study is part of the research consortium Improving the Information Base and Optimizing Service Solutions to Support Social Welfare and Health Care Reform (IMPRO) 312703.

Conference presentation: part of this paper was presented at the Annual Meeting of the American Association of Geographers, 2019 April 3-7, Washington, DC, USA.

Received for publication: 29 August 2019

Revision received: 4 October 2019.

Accepted for publication: 5 October 2019.

${ }^{\circ}$ Copyright: the Author(s), 2019

Licensee PAGEPress, Italy

Geospatial Health 2019; 14:809

doi:10.4081/gh.2019.809

This article is distributed under the terms of the Creative Commons Attribution Noncommercial License (CC BY-NC 4.0) which permits any noncommercial use, distribution, and reproduction in any medium, provided the original author(s) and source are credited. stroke. Currently, two major drug therapies are available: warfarin and direct oral anticoagulant (DOAC). This study examined the spatial costs of these therapies and derived the least-cost market areas for both therapies in the study area. The concepts of spatial costs and the principles of forming market areas were used as theoretical starting points, and the patients' travel, time-loss, and medication cost parameters combined with geographical information systems methods were incorporated into the geospatial model. Results showed that for AF patients who live near the international normalized ratio (INR) monitoring sample collection point and have less than 15 annual INR monitoring visits, warfarin therapy resulted in the lowest cost regardless of patient's travel mode and their assumed working or retirement status. If the AF patient needs more frequent INR monitoring visits or lives farther from the nearest sample collection point, DOAC would be the least costly option. The modelled results reveal the variety and importance of patients' cost of time loss and travel costs when a physician selects the appropriate anticoagulation therapy.

\section{Introduction}

Currently in Europe, atrial fibrillation (AF) affects 9 million people, and its increasing prevalence raises the expenditures for the health care sector (Krijthe et al., 2013; Zoni-Berisso et al., 2014). In addition to societal costs, patients incur notable time costs and direct monetary travel costs for regular follow-up visits (Jowett et al., 2008; Hwang et al., 2011).

$\mathrm{AF}$ is the most common form of cardiac arrhythmia, and its prevalence increases with age. The prevalence is 1.9\%-2.9\% in Western countries, and the average age of AF patients falls between 75 and 84 (Zoni-Berisso et al., 2014). AF is associated with a risk of thromboembolic events and stroke (Amin, 2013; Verhoef et al., 2014). Oral anticoagulation therapy is used for the prevention of a stroke and systemic embolism for patients who have a high risk of complications (Hallinen et al., 2014). Finnish treatment guidelines recommend the use of anticoagulation therapy when a score between 1 and 2, based on CHA2DS2-VASc risk estimation, is reached (Hammersley and Signy, 2017; The Finnish Medical Society Duodecim, 2018).

Warfarin is a popular and inexpensive drug for anticoagulation therapy and used worldwide for decades. However, the drug has many adverse food interactions, which affects its pharmacokinetics (Ansell et al., 2008). Frequent monitoring of the international normalized ratio (INR) and drug dose adjustment are part of war- 
farin therapy to achieve the desired treatment targets (Hallinen et al., 2014). INR monitoring incurs costs, both for the health care sector and the patients, and it raises the total cost of therapy for AF patients using this drug (Parry et al., 2001; Schulman et al., 2010). The Finnish Current Care Guidelines for AF recommend that the INR should be monitored once a month, but the monitoring frequency can be higher when the INR is outside the therapeutic range (The Finnish Medical Society Duodecim, 2018).

Direct oral anticoagulants (DOACs) became available as an alternative to warfarin during the past decade. Clinical trials have shown that the efficacy of DOACs is similar to warfarin (Connolly et al., 2009; Granger et al., 2011; Patel et al., 2011), while the advantage is that these drugs prevent thromboembolic complications without regular monitoring (Silingardi, 2013). DOACs have significantly less adverse interaction with food and drugs than warfarin, which allows fixed dosing (Testa et al., 2012). However, DOAC drugs are more expensive than warfarin, and chronic kidney disease and a mechanical heart valve are contraindications for the use of DOACs (Hinojar et al., 2015).

In Finland, DOACs are partially reimbursable for non-valvular AF patients whose CHA2DS2-VASc score is $\geq 1$ (The Finnish Medical Society Duodecim, 2018). After reimbursement by the Social Insurance Institution of Finland, the daily drug cost of DOACs is currently between $0.93-1.01 €$, depending on which specific DOAC drug is prescribed, while the corresponding cost of warfarin is $0.07 €$ per day. The slow spread of DOACs may result from the relatively high drug cost for the patient. However, frequent journeys to a sample collection point increase his or her cost for warfarin therapy. These additional costs narrow the cost difference between warfarin and DOAC therapies, and hence the price of warfarin is only a small part of the total cost of warfarin therapy (Schulman et al., 2010).

Previous assessments of this cost difference have mostly been assessed from a health care sector perspective based on qualityadjusted life-years (Coyle et al., 2013; Verhoef et al., 2014). However, Marcolino et al. (2016) investigated the costs using costminimization analysis from a societal perspective including the effect of patient travel costs and the cost of time lost in warfarin therapy, finding that DOAC therapy in fact incurred a lower cost, at least for some patients.

The cost difference between warfarin therapy and DOAC therapy has decreased. However, earlier studies have excluded the least-cost optimisation for a patient between these two therapies, including the cost of travel and time lost in health care districts. To fill this research gap, our study aimed to develop a geospatial model that can be used to determine the optimal allocation of both therapies. We used the North Karelia health care district in Finland as study area.

\section{Materials and Methods}

\section{Study area and population}

The study area consisted of 14 municipalities (13 in North Karelia and one, Heinävesi, in Southern Savonia) with a total population of 166,000 at the end of 2017 (Statistics Finland, 2017). The population density is low $\left(9.3\right.$ per $\left.\mathrm{km}^{2}\right)$, which is a challenge for the delivery of cost-efficient health care service, especially in small centres and rural areas.
Blood samples for INR monitoring can be taken in 25 sample collection points at health care centre premises. These sample collection points are located mainly in municipality centres. The distance to the closest sample collection point is short for most of the population but relatively long (sometimes over $60 \mathrm{~km}$ ) for a patient living in an outlying district.

\section{Study design}

We investigated the spatial costs of warfarin therapy and DOAC therapy from the AF patients' least-cost perspective and derived the market areas for both therapies. The least-cost optimisation was done by measuring the patients' travel, time-loss, and medication costs as annual expenditures. The optimisation of the least-cost anticoagulation therapy was implemented by applying a theoretical background of industrial location formulated by Tord Palander (Smith, 1981). We modified the principles of Palander's market area theory to suit our research task and geospatial model (Figure 1).

The total cost of warfarin therapy $\left(\mathrm{TC}_{\mathrm{wvi}}\right)$ consists of the cost of the drug $\left(\mathrm{P}_{\mathrm{w}}\right)$, the fixed costs of a monitoring visit $\left(\mathrm{FC}_{\mathrm{v}}\right)$ and the extent of a travel cost per visit. Hence, the cost of warfarin therapy is the lowest for patients who live near a sample collection point and have a low number of annual INR monitoring visits. The total cost of DOAC therapy $\left(\mathrm{TC}_{\mathrm{DOAC}}\right)$ is both spatially and annually fixed. Thus, we compared a variable cost of warfarin therapy with this constant cost of DOAC therapy by creating the different INR monitoring visit scenarios having a variable total $\operatorname{cost}\left(\mathrm{TC}_{\mathrm{wvi}}\right)$ when warfarin is used (Figure 1). The maximum $\mathrm{TC}_{\mathrm{wvi}}$ consists of the warfarin price, INR monitoring and the maximum cost-efficient travel cost $\left(\mathrm{P}_{\mathrm{w}}+\mathrm{FC}_{\mathrm{v}}+\mathrm{MaxC}_{\mathrm{v}}\right)$; it is used to determine the spatial joint isocost lines of both therapies. These isocost lines were calculated separately for different INR monitoring frequencies by travel mode and working/retirement status, and the market areas were determined for both therapies by applying these lines in spatial analyses.

Figure 1 shows the theoretical gradients of the total cost when a patient on warfarin therapy has, as an example, one or two annual INR monitoring visits. The steepness of a gradient depends on the travel cost function of the travel mode and the number of annual INR monitoring visits. The boundaries of market areas $\left(\right.$ Area $_{w}$, Area $_{\text {DOAC }}$ ) were determined using the intercept of the gradient and the total cost of DOAC therapy. The distance in the intercept, the cut-off distance, is the maximum cost-efficient travel distance from the sample collection point to the cut-off isocost line in warfarin therapy.

Based on this framework, we constructed a geospatial model using ArcGIS Pro (ESRI, Redlands, CA, USA) and Python software (https://www.python.org/psf/). The flowchart of the model is presented in Figure 2. The model has two main sections: input data and spatial analyses. First, constrained by the fixed DOAC medication cost, the model calculates the maximum cost-efficient travel cost for different INR monitoring visits scenarios in warfarin therapy, separately for working persons and retirees by travel modes. This information is used as input data in geospatial derivation of the boundaries of the market areas. Lastly, these calculated values are used in spatial analyses one by one, and the market areas of both therapies are derived for the different INR monitoring visits scenarios by travel mode.

\section{Assessment of cost parameters}

The coefficients of the geospatial model consist of parameters 
depicting the cost of time loss, the costs of travel, and drug costs (Figure 2). The cost functions and parameters were derived from the data of the study area, but the model can be recalibrated with distinct cost parameters, and it can be applied to different geographical areas. The input parameters of the model are shown in Table 1.

The INR monitoring visit encompasses various cost elements in addition to the transport cost. The time costs of warfarin therapy consist of the travel time to a sample collection point, the time spent there and the time used for dose adjustment at home (Jowett et al., 2008). The time lost for the patients was converted to a monetary cost by multiplying by the hourly value of time (VOT), calculated using the average hourly income in the study area (Statistics Finland, 2019). In the model, travel time was calculated door-to-door (Salonen and Toivonen, 2013; Tenkanen et al., 2016) and separately for different travel modes. Thus, the whole round trip between a starting point and the sample collection point was covered by the time cost calculation (Table 1).

Earlier studies (Johannesson et al., 1991; Jowett et al., 2008; Leminen et al., 2018) used a coefficient to value the lost working and leisure time. In our study, the value coefficient of a patient's lost time (TL) had two different values. The TL for a working per- son was set as equal to the average hourly income in the study area, while a retiree's TL was valued as $35 \%$ of the average hourly income. The division between subgroups was based on the current lowest retirement pension age (64 years of age).

Travel cost functions and parameters were set by travel mode. The direct travel costs of private car, taxi and bus were based on the current operating expenses and charges in the study area (Table 1). For taxi, the maximum direct monetary cost for a one-way trip was set at $25 €$ because the Social Insurance Institution of Finland reimburses a patient's health care related travel costs when the one-way cost exceeds $25 €$ and travelling complies the criteria (Social Insurance Institution of Finland, 2019). Additionally, an upper limit of $300 €$ was considered for the annual travel cost reimbursement. Bus fares were set based on the average cost of a single ticket in the Joensuu region, as it is the only subregion where public transport is available in the study region.

The drug costs were retrieved from the database of Association of Finnish Pharmacies (Association of Finnish Pharmacies, 2018). Four different DOAC drugs (rivaroxaban, edoxaban, dabigatran and apixaban) were placed into two classes by the annual out-ofpocket cost for patients. The DOACs prices were based on the lower special rate of reimbursement $(65 \%)$, and the price of war-

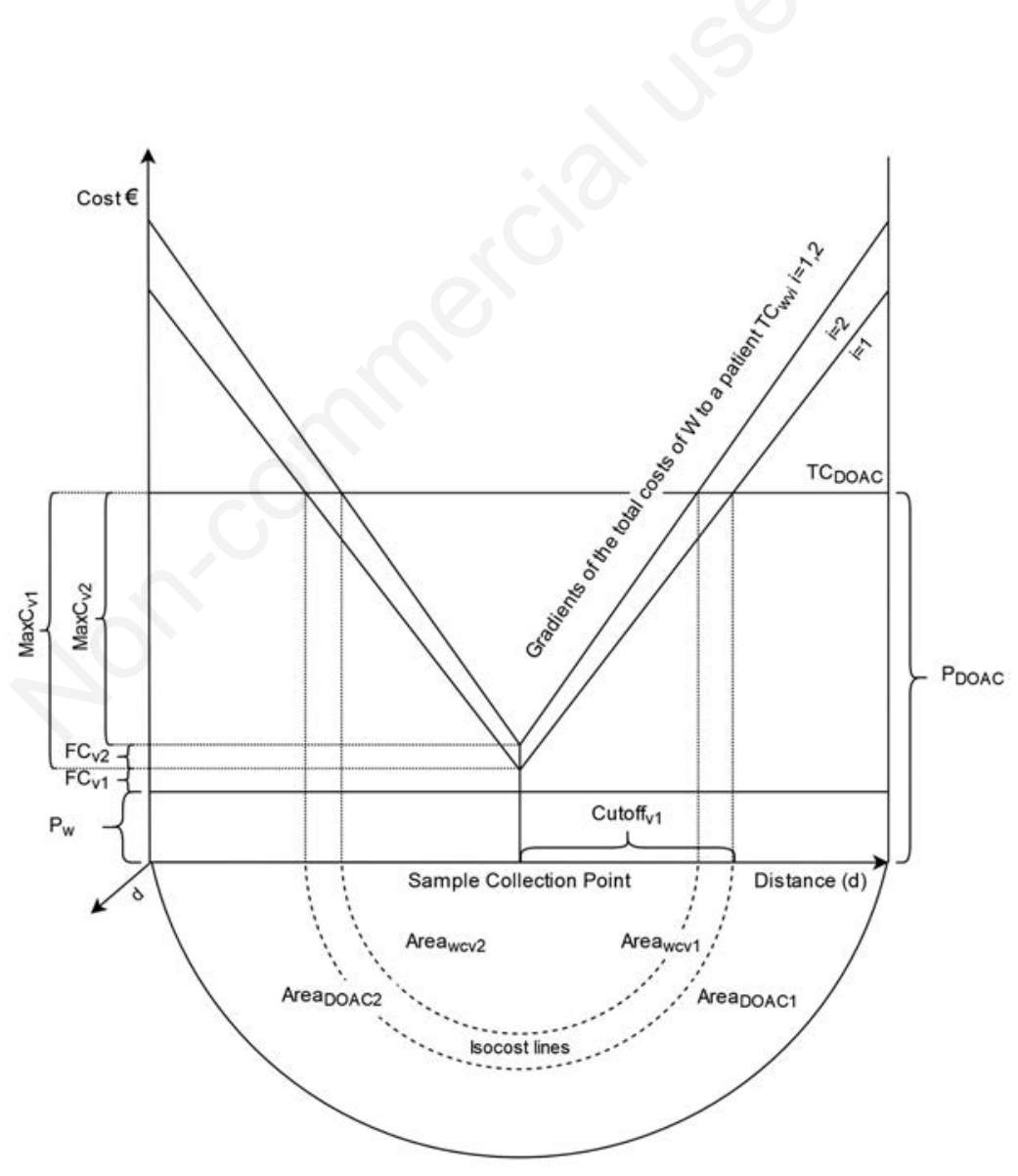

Figure 1. Derivation of boundaries between the market areas of warfarin therapy and direct oral anticoagulant (DOAC) therapy. The size of market areas is influenced by drug prices, the fixed costs of a monitoring visit, the number of sample collection point visits, and travel cost in warfarin therapy. Cut-off distance is the distance between the isocost line and the sample collection point. $\mathrm{P}$, price of medicine; TC, total costs of therapy; MaxC, maximum travel cost; FC, fixed cost per visit; Cut-off ${ }_{\mathrm{v} 1}$, cut-off distance with 1 visit; Area ${ }_{\text {DOACi }}$, area for DOAC if patient has ' $i$ ' visit in warfarin therapy; $w$, warfarin; $v_{1}$, one visit; $v_{2}$, two visits. 
farin on the basic rate of reimbursement (40\%).

By using patient register data from the same region, researchers have shown that the average annual INR monitoring frequency is 19.1 (standard deviation=13.7) in the Joensuu region (Hallinen et al., 2014). Based on these findings, we scaled the annual INR monitoring frequency from 6 to 30 to represent the variation in the annual INR monitoring frequency in the model.

\section{Equations to solve the maximum cost-efficient travel cost in warfarin therapy}

The maximum travel cost by INR monitoring visits $\left(\mathrm{MaxC}_{\mathrm{vi}}\right)$ for warfarin therapy had to be calculated before the geospatial derivation of the boundaries of the market areas because the market areas for the therapies are defined based on their isocost line values. The annual cost of DOAC therapy was used as the baseline and the starting point when the isocost lining was implemented between warfarin and DOAC therapy (Figure 1).

We calculated the maximum travel cost in warfarin therapy for four travel modes because patients use diverse travel modes when they travel to a sample collection point (Figure 2). These costs vary between travel modes and, according to Rodrigue et al. (2009), the monetary cost is often the most important criterion for choosing a travel mode. Following this, we utilised a modified door-to-door approach (Salonen and Toivonen, 2013) for our geospatial model for the four different travel modes, applying the study by Ford $e t$ al. (2015).

In our study area, the main modes of travel are by private car $\left(\mathrm{C}_{\mathrm{CAR}}\right)$, taxi $\left(\mathrm{C}_{\mathrm{TAXI}}\right)$, walking $\left(\mathrm{C}_{\mathrm{WALK}}\right)$, and public transport $\left(\mathrm{C}_{\mathrm{BUS}}\right)$. The maximum travel cost per INR monitoring visit was calculated separately for the different travel modes by the age groups and by the annual INR monitoring frequencies. Because we observed that the travel costs are linearly dependent on distance and TL, formu- las for different travel modes were set using linear Eqs. 1a-1d:

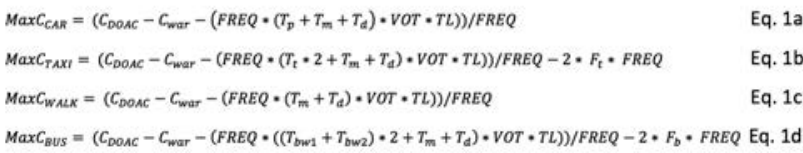

where $\mathrm{C}_{\mathrm{DOAC}}$ is the annual cost of DOAC after reimbursement; $\mathrm{C}_{\mathrm{WAR}}$ the annual cost of warfarin after reimbursement; FREQ the annual INR monitoring frequency, $\mathrm{T}_{\mathrm{p}}$ the parking time; $\mathrm{T}_{\mathrm{t}}$ the taxi service time; $T_{m}$ the time spent in INR monitoring; $T_{d}$ the time estimate for dose adjustment in warfarin therapy; VOT the average hourly gross wage of the health care district; TL the value coefficient of lost time; $\mathrm{T}_{\mathrm{bw} 1}$ the average waiting time at a bus stop; $\mathrm{T}_{\mathrm{bw} 2}$ the walking time to a bus stop; $F_{t}$ the fare paid for the taxi journey; and $\mathrm{F}_{\mathrm{b}}$ the fare paid for the bus journey. The detailed coefficient values can be seen in Table 1 .

All fixed costs of warfarin therapy were added to the Eqs. 1a$1 \mathrm{~d}$, including the fixed costs during INR monitoring visits travels. The door-to-door approach was simplified by assuming fixed walking times to connecting points and fixed waiting and service times (Table 1). The Eqs. 1a-1d outputs reveal the maximum monetary cost, which a patient can spend for travelling when the annual costs of both therapies are set equal and the frequency and the costs of INR monitoring are considered.

\section{Preparation of digital road network and travel imped- ances}

The road network and the locations of the sample collection points were used in the geospatial travel modelling (Figure 2). We used the Digiroad database from the Finnish Transport Agency

Table 1. Parameters used in the geospatial model.

\begin{tabular}{|c|c|c|}
\hline Parameter & Description & Value used in analysis \\
\hline VOT & Based on average hourly income of North Karelia & $10.30 € / h$ \\
\hline Value coefficient of a patient's TL & $\begin{array}{c}\text { Working time valued as } 100 \% \text { of VOT, and leisure time of } \\
\text { a retiree valued as 35\% of VOT }\end{array}$ & Working person: 1 \\
\hline $\mathrm{T}_{\mathrm{m}}$ & Time spent in the international normalized ratio monitoring visit & $20 \mathrm{~min}$ \\
\hline $\mathrm{T}_{\mathrm{d}}$ & Time spent for dose adjustment of warfarin after monitoring & $10 \mathrm{~min}$ \\
\hline $\mathrm{T}_{\mathrm{p}}$ & Time spent for private car parking & $5 \mathrm{~min}$ \\
\hline $\mathrm{T}_{\mathrm{t}}$ & Service time of taxi & $5 \mathrm{~min}$ \\
\hline $\mathrm{T}_{\mathrm{bwl}}$ & Waiting time at a bus stop & $7 \mathrm{~min}$ \\
\hline $\mathrm{T}_{\mathrm{bw} 2}$ & Walking time to a bus stop & $5 \mathrm{~min}$ \\
\hline $\mathrm{VOC}_{\mathrm{c}}$ & Vehicle operating cost for private car & $0.45 € / \mathrm{km}$ \\
\hline $\mathrm{VOC}_{\mathrm{t}}$ & Charge for taxi & $1.59 € / \mathrm{km}$ \\
\hline $\mathrm{F}_{\mathrm{t}}$ & Initial charge of taxi & $5.90 €$ \\
\hline $\mathrm{F}_{\mathrm{b}}$ & Fare paid for the journey by bus & $3.80 €$ \\
\hline $\mathrm{S}_{\mathrm{b}}$ & Average speed of bus & $30 \mathrm{~km} / \mathrm{h}$ \\
\hline $\mathrm{S}_{\mathrm{w}}$ & Average speed of walking & $3.5 \mathrm{~km} / \mathrm{h}$ \\
\hline $\mathrm{C}_{\text {war }}$ & Annual cost of warfarin after reimbursement & $25.50 €$ \\
\hline $\mathrm{C}_{\mathrm{DOAC}}$ & Annual cost of direct oral anticoagulant after reimbursement & $\begin{array}{l}\text { Dabigatran and apixaban }=369.30 € \\
\text { Rivaroxaban and edoxaban }=338.30 €\end{array}$ \\
\hline FREQ & Frequency of monitoring visits per year & 6 to 30 \\
\hline
\end{tabular}




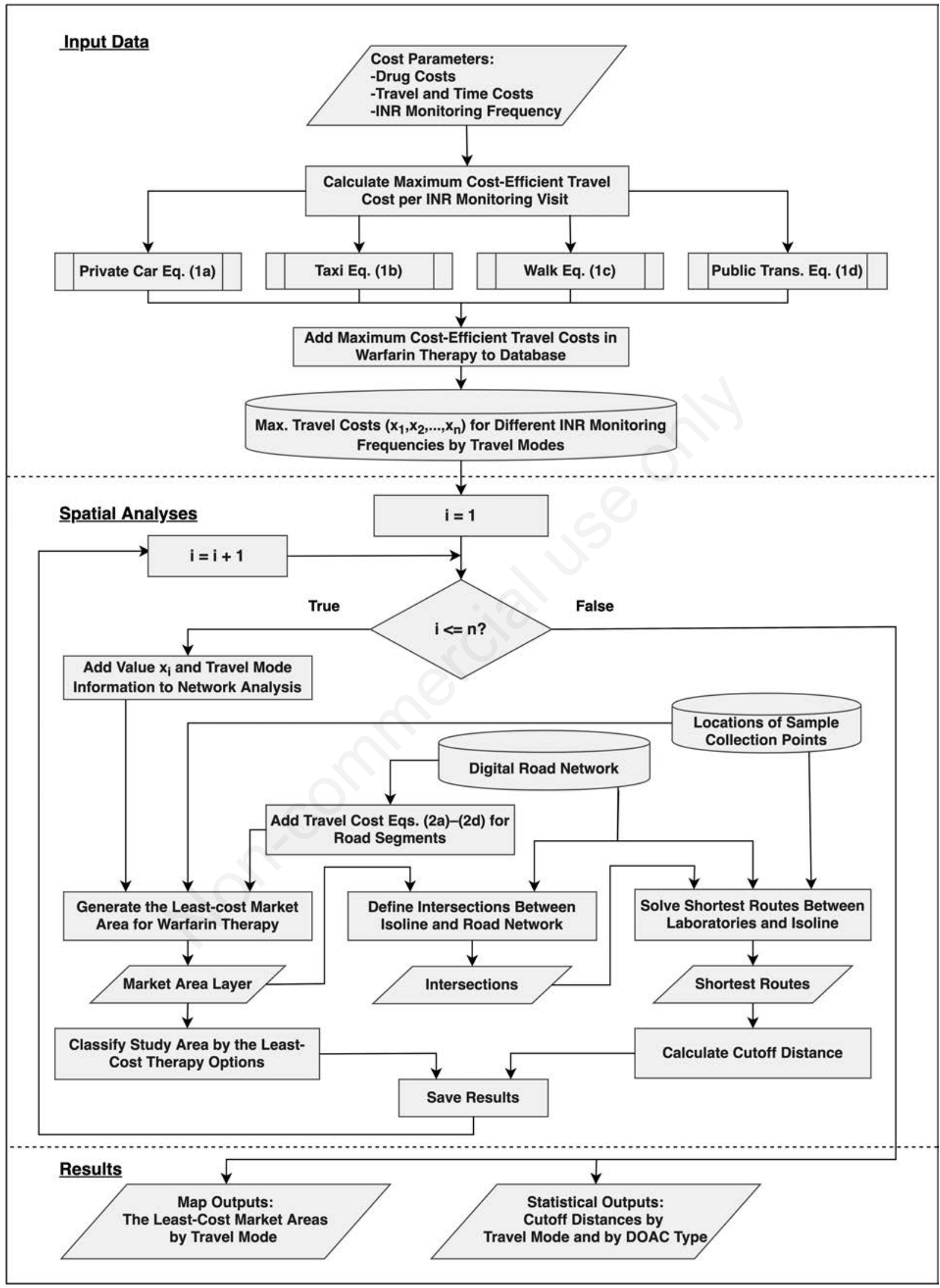

Figure 2. Flowchart of the geospatial model to the derivation of the market areas of warfarin therapy and direct oral anticoagulant therapy in a health care district. INR, international normalized ratio; DOAC, direct oral anticoagulant. 
modifying it to fulfil the demands of the model. For example, traffic impediments (e.g., traffic lights and intersection delays) were added to the network.

The model utilised temporal and spatial attributes of road segments in the analyses. We applied travel time and distance in the equations to calculate the total travel cost of road segments by travel modes. Eqs. $2 \mathrm{a}-2 \mathrm{~d}$ express the travel costs by private car $\left(\mathrm{C}_{\mathrm{CAR}}\right)$, taxi $\left(\mathrm{C}_{\mathrm{TAXI}}\right)$, walking $\left(\mathrm{C}_{\mathrm{WALK}}\right)$, and public transport $\left(\mathrm{C}_{\mathrm{BUS}}\right)$ in the road network:

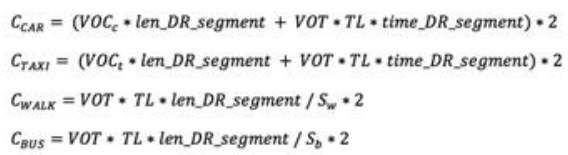

where VOC is the vehicle cost per km; VOT the average hourly gross wage in the health care district; TL the value coefficient of lost time; $S_{w}$ the patient's average walking speed; $S_{b}$ the bus average speed; len_DR_segment the length of the road segment in question; and time_DR_segment the travel time for this road segment by car.

\section{Determining the minimum costs of therapies for a patient}

The least-cost market areas of therapies for patients were derived by applying the two aspects of spatial accessibility in the geospatial model (Guagliardo, 2004). These two aspects - the availability and accessibility of health care - were considered in the model when we included the sample collection points and measured the accessibility by using the road network.

Two different network analysis methods were used when modelling the least-cost therapy option. First, we applied Service Area Analysis (ESRI, 2018a) to assess the least-cost market areas for both anticoagulation therapies (Figure 2). For inputs, we used the maximum travel costs of an INR monitoring visit, calculated earlier using Eqs. 1a-1d for different monitoring scenarios. Travel costs of travel modes in the road network were set separately using Eqs. $2 \mathrm{a}-2 \mathrm{~d}$ in these analyses. After each Service Area Analysis, the Origin-Destination Cost Matrix (ESRI, 2018b) method was used to solve the travel distance from a sample collection point to the cutoff isocost line of the market areas (Figure 2). These cut-off distances were calculated by utilising the output of the Service Area Analysis, the locations of the sample collection points and the road network.

\section{Sensitivity analyses}

We performed sensitivity analyses for the annual cost of DOAC drugs. The cost of the DOACs was reduced by $25 \%$ from the annual cost of our research period, following the assumption that the drug costs would decrease after DOACs become more commonly used and generic drugs are introduced. Other parameters were left untouched when applying the sensitivity analyses. Sensitivity analyses were also performed to investigate the functionality and stability of the model when input data changed.

\section{Results}

The cut-off distances of the market areas are presented in Figure 3. These cut-off distances varied between 0 and $58 \mathrm{~km}$ when an INR monitoring frequency of 6 to 30 was considered by travel modes in the model. The cut-off distances were based on the prices of rivaroxaban or edoxaban in DOAC therapy. When comparing the cost-efficiency of warfarin therapy with DOAC therapy with dabigatran and apixaban, the cut-off distances were slightly longer in all cases due to the lower retail price of these DOACs.

The results show that the widest least-cost market area for warfarin therapy was achieved by private car. For example, the cut-off distance for warfarin therapy with 12 annual INR monitoring visits was $15.5 \mathrm{~km}$ for a working person and $23.0 \mathrm{~km}$ for a retiree. With higher INR monitoring frequencies, private car was still the most cost-efficient travel mode, but the cut-off distances shrank slowly when the frequency increased.

The model would produce even longer cut-off distances for public transport, but the size of the available public transport network limits the range of usage to the surroundings of the city of Joensuu. However, the cut-off distance decreased rapidly when the INR monitoring frequency increased, leading to the situation that travelling by public transport is not affordable for working persons on warfarin therapy (if freq $\geq 19$ ) and retirees (if freq $>30$ ), not even for short distances. In this case, DOAC therapy emerges as the least-cost option, regardless of travel distance and domicile location (Figure 3). By walking, warfarin therapy is the least-cost therapy option for patients living in the relatively large areas around sample collection points, but the value of time has a substantial impact on the extent of these areas between working persons and retirees. Walking to INR monitoring was found to be cost-efficient from $3.6 \mathrm{~km}$ for a working person, even unrealistically up to 11.8 $\mathrm{km}$ for a retiree due to affordability of walking when the number of annual follow-up visits was 12 (Figure 3).

The smallest least-cost market area for warfarin therapy is reached when taxi is used as it is the most expensive travel mode in the model. The maximum cost-efficient travelling distance for a one-way trip by taxi was $2.0 \mathrm{~km}$ for a working person and $3.5 \mathrm{~km}$ for a retiree when the number of annual follow-up visits was 12 . Due to high direct monetary travel costs, taxi is not a cost-efficient travel mode for frequent travelling at any distance for working persons on warfarin therapy (if freq $\geq 17$ ) and retirees (if freq $\geq 21$ ).

The market areas of the therapies for a working person are visualised in Figure 4. Private car, taxi, walking and public transport were all feasible travel modes with regard to warfarin therapy when a working person does not live far from the sample collection point and the frequency of follow-up visits follows the normal care guidelines. DOAC therapy was mostly the least-cost option in rural areas, but the frequent use of taxi or public transport for warfarin therapy makes DOAC therapy the least-cost option also in some urban areas for working persons.

Figure 5 presents the market areas of therapies for a retiree when the patient has the recommended number of INR monitoring visits. Warfarin therapy seems to be the least-cost option for every travel mode in the most populated areas when the annual INR monitoring frequency is simulated by 10,14 and 18 visits. The widest market area was reached by private car (freq $=10$ ), and this area covers almost the whole study region with exception of the most outlying rural areas (Figure 5). Only the combination of taxi and warfarin therapy was partly limited in urban areas from the least-cost point of view for retirees.

Sensitivity analysis shows how the DOAC price reduction expands the market area of DOAC therapy as the least-cost therapy (Figure 3). The effect of price reduction was strongly cutting taxi rides and public transport when warfarin is used. If the price of 
DOAC can be reduced by $25 \%$, DOAC therapy will become the least-cost option everywhere for a working person using a taxi for more than 12 visits or public transport for more than 14 visits annually. Moreover, after the price reduction, the market area of warfarin therapy for a working person was limited to a small area by walking. For a retiree, the warfarin therapy combined with trav- elling by taxi was the least-cost option only if the patient requires less than 16 annual visits; even then, only from the close vicinity of a sample collection point. The influence of the DOAC price reduction would also have an effect on the patients who travel by private car, shifting the borderline of the least-cost market area of warfarin therapy closer to urban areas.
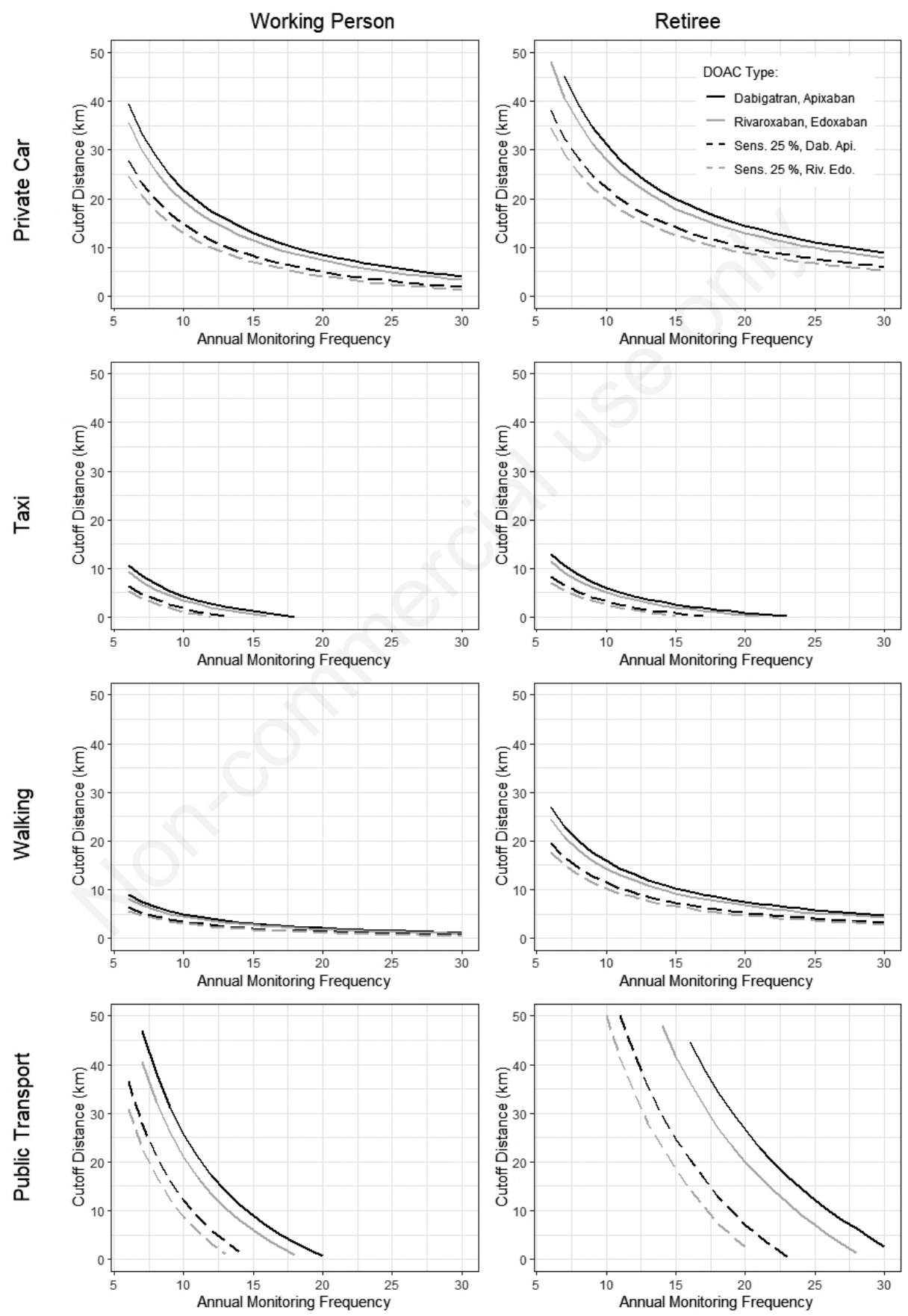

Figure 3. The cut-off distances of therapy market areas for a working person and a retiree by travel modes. The figure contains the results for both direct oral anticoagulant (DOAC) price classes and the outcome of sensitivity analyses. The area below the curve shows the distances and international normalized ratio monitoring frequency when warfarin therapy including traveling is the least-cost option for a patient, and the area above the curve shows the respective values when DOAC therapy becomes the least-cost option. 
Taxi
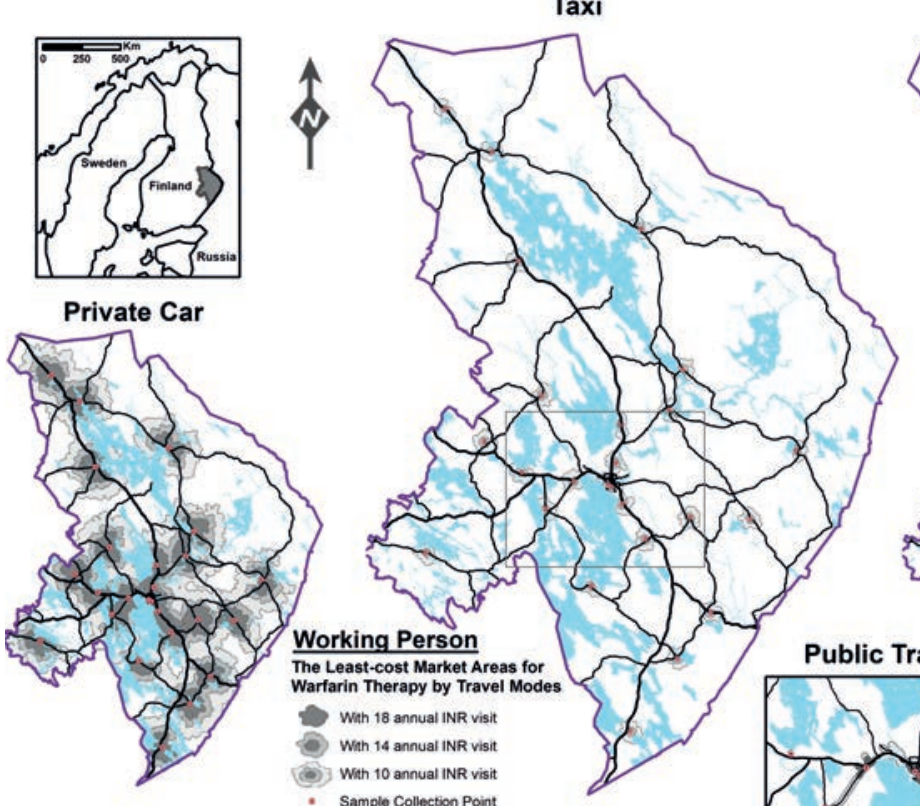

\section{Working Person} The Least-cost Market Areas for Warfarin Therapy by Travel

Wah 14 annual INR visit

(6) Wah 10 annual INR visit

\begin{tabular}{llll}
0 & $20 \quad 40 \quad 80$ \\
\hline
\end{tabular}

- Sample Collection Point

- Main roads

Public Transpon

Water areas

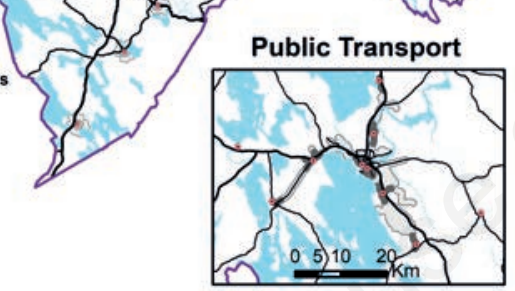

Walking

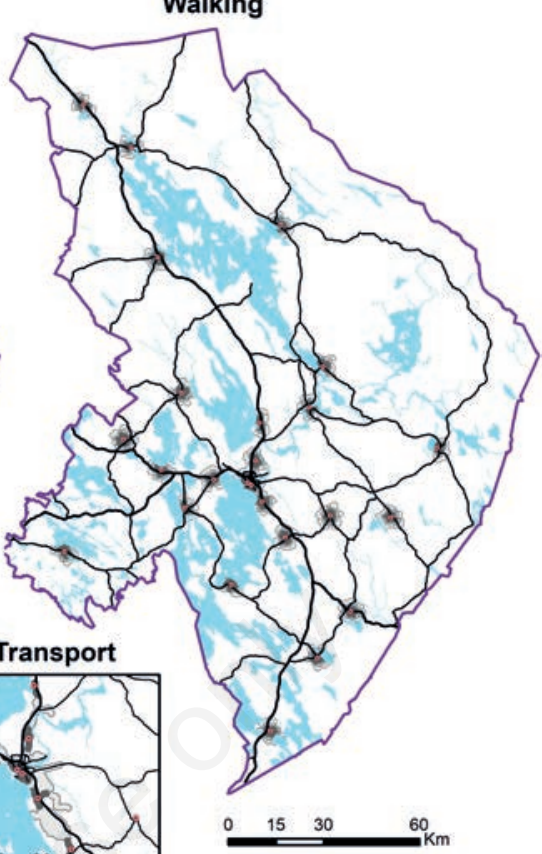

Figure 4. The least-cost market areas of anticoagulation therapies for a working person. 10, 14 and 18 annual international normalized ratio (INR) monitoring visits were used as inputs. Three classes of market areas (grey shades) show warfarin therapy. Direct oral anticoagulant therapy is more affordable for patients in the areas outside each particular class.
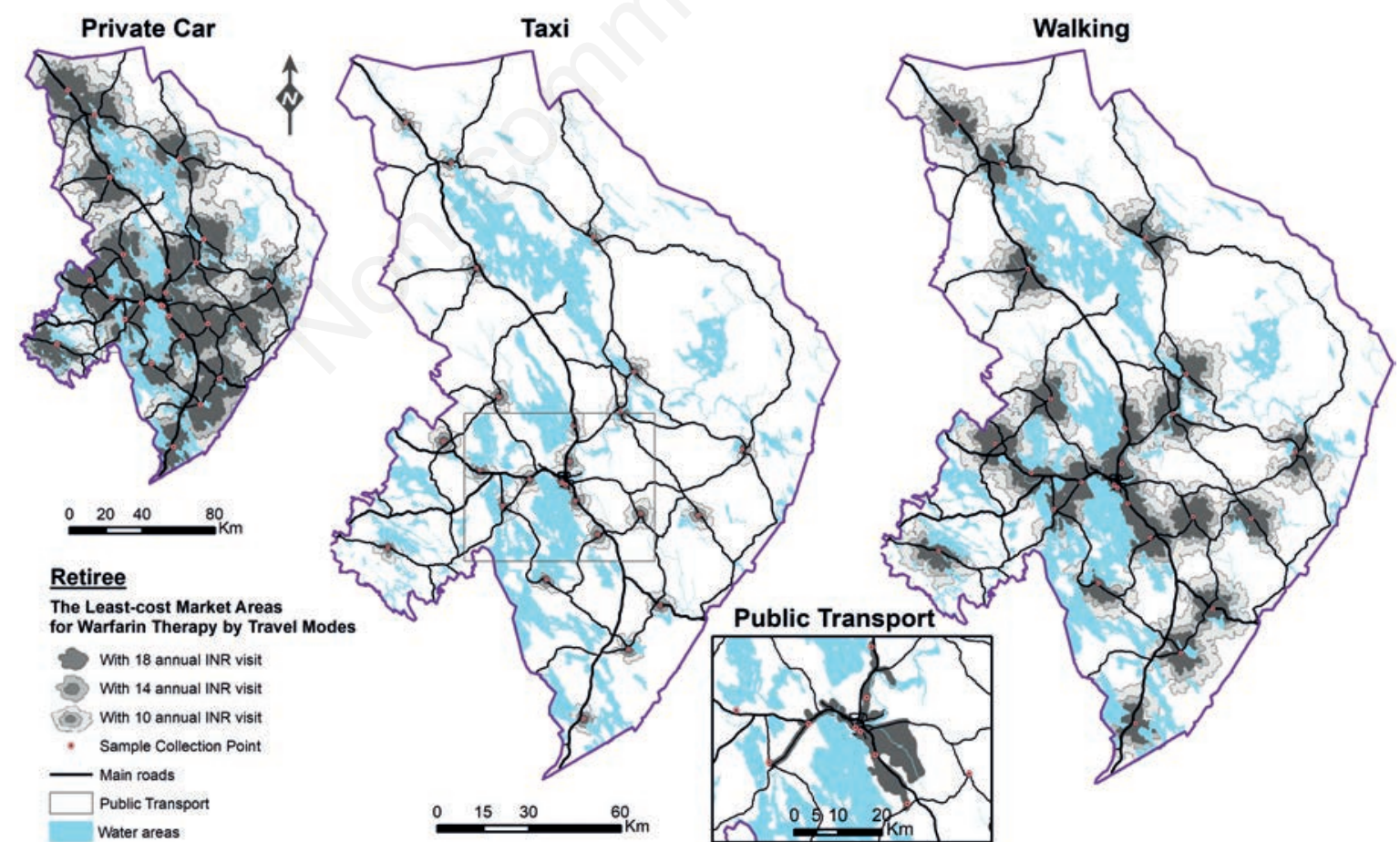

Figure 5. The least-cost market areas of anticoagulation therapies for a retiree. 10, 14 and 18 annual international normalized ratio (INR) monitoring visits were used as inputs. Three classes of market areas (grey shades) show warfarin therapy. Direct oral anticoagulant therapy is more affordable for patients in the areas outside each particular class. 


\section{Discussion and Conclusions}

The aim of the study was to create a general geospatial model that can be used to determine the optimal allocation of anticoagulation therapies for different geographical areas from the AF patients' perspective. The model was tested in the area of North Karelia, and the outputs of the model can be reliably applied in the Finnish context and should be tested also in other areas.

Our results show that in both age groups, warfarin therapy is the least-cost option in the close vicinity of the sample collection points with all four travel modes when the patients do not require more than the recommended number of INR monitoring visits. By private car, warfarin therapy is also the least-cost option in the majority of rural areas. Respectively, DOAC therapy is spatially the least-cost option for AF patients who live farther away from the INR sample collection points, or whose annual INR monitoring frequency is high despite the location of the domicile. Both the frequency of INR monitoring visits and the travel mode used in warfarin therapy substantially affect the size of the least-cost market areas of anticoagulation therapies. Additionally, the valuation of time causes remarkable differences in the spatial costs of therapies between working persons and retirees.

In the sensitivity analyses, we simulated a reduction of the annual DOAC prices to investigate how it would influence on the extents of the market areas of warfarin and DOAC therapies. The size of least-cost market areas for DOAC therapy increases when the drug price falls. The price reduction of $25 \%$ leads to a situation where regular travelling to INR monitoring by taxi or public transport in no more the optimal option for a working person anywhere, as DOAC therapy becomes cheaper. For a retiree, warfarin therapy is still the least-cost option in most cases near the sample collection points, although the distance must be short by taxi. The model showed its faultless appropriateness in sensitive analyses and all stages of model runs and in different INR monitoring scenarios.

Marcolino et al. (2016) described potential patient profiles for whom the shift from warfarin to DOAC therapy could be economically attractive in Brazil. The results from this study show that DOAC therapy would be appropriate among non-elderly patients due to the higher costs of TL, and among patients living at least 20 $\mathrm{km}$ away from a sample collection point, because transportation causes more significant travel costs. Both patient profiles of DOAC users match our results, but in some cases, our model produced even shorter distances due to the lower out-of-pocket drug costs in our study area.

Patient costs are difficult to compare due to the completely different execution of these two anticoagulation therapies. To improve the knowledge of the spatial cost-efficiency of the anticoagulation therapies, we offer a new computational method to the spatial targeting of the least-cost anticoagulation therapy. Earlier studies have mostly compared the costs of therapies from the perspective of service costs (Verhoef et al., 2012; Coyle et al., 2013; Salata et al., 2016). Our model demonstrates the selection of the least-cost option of anticoagulation therapies from the patient perspective. Both physicians and patients can utilise the new information of the least-cost therapy option, which might increase the use of DOACs for patients living farther away from sample collection points and among those with a high frequency of INR monitoring visits. Moreover, the increase in the use of DOACs can lead to improvements in the quality of care, as DOACs have been shown to decrease the rate of strokes and other complications more efficiently (Verhoef et al., 2014).
In the study area, the availability of a public transport network is mainly limited to the town of Joensuu, and the bus routes cover only the most populated areas with variable service frequency. Thus, the calculations of realistic spatial costs for public transport is challenging. The cost was determined by using the digital road network with constant fare parameter for the public transport. In the areas of higher public transport density than in this study area, to achieve spatially more accurate results of the travel costs with respect to the therapies used, more comprehensive accessibility calculation methods, such as multimodal accessibility measurements with temporal aspects, should be applied for public transport journeys (Tenkanen et al., 2016).

A potential source of uncertainty is the assumption that every taxi ride had to be organised individually for each patient. The Social Insurance Institution of Finland (2019) has started to use taxi ridesharing, and part of the reimbursable journeys are organised this way. The modelled cut-off distances are accurate when a patient pays the full price of the journey and reimbursement of the health care related travel cost has been considered. When patients share the cost of a taxi journey, it reduces the monetary travel costs. On the other hand, sharing a journey might increase the total time of an INR monitoring visit, and thus the cost, which could lead to even higher travel costs.

Our geospatial model can be developed and expanded to suit different geographical areas. By changing the main cost parameters and applying the local digital road network, the model can be used without any need for modifications. It can also be utilised to determine for the least-cost options of different drugs and treatment processes, which can be done, either from the patient's or the health care sector's point of view. However, the maximum limit of time spent travelling should be taken account if the model is applied at the individual level. The cost related to potential complications of warfarin and DOAC therapy was not considered in the geospatial model, but this amendment can be added to the model when the outcomes of AF patients have been followed long enough. Additionally, the model can be developed to utilise electronic patient register data, after which the least-cost anticoagulation therapies can be calculated for AF patients individually.

\section{References}

Amin A, 2013. Oral anticoagulation to reduce risk of stroke in patients with atrial fibrillation: current and future therapies. Clin Interv Aging 8:75-84.

Ansell J, Hirsh J, Hylek E, Jacobson A, Crowther M, Palareti G, 2008. Pharmacology and management of the vitamin K antagonists: American College of Chest Physicians Evidence-Based Clinical Practice Guidelines (8th edition). Chest 133:160S98S.

Association of Finnish Pharmacies, 2018. Association. Available from: https://www.apteekkariliitto.fi/en/association.html Accessed: December 5, 2018.

Connolly SJ, Ezekowitz MD, Yusuf S, Eikelboom J, Oldgren J, Parekh A, Pogue J, Reilly PA, Themeles E, Varrone J, Wang S, Alings M, Xavier D, Zhu J, Diaz R, Lewis BS, Darius H, Diener HC, Joyner CD, Wallentin L, RE-LY Steering Committee and Investigators, 2009. Dabigatran versus warfarin in patients with atrial fibrillation. $\mathrm{N}$ Engl $\mathrm{J} \mathrm{Med}$ 361:1139-51.

Coyle D, Coyle K, Cameron C, Lee K, Kelly S, Steiner S, Wells 
GA, 2013. Cost-effectiveness of new oral anticoagulants compared with warfarin in preventing stroke and other cardiovascular events in patients with atrial fibrillation. Value Health 16:498-506.

ESRI, 2018a. ArcGIS for desktop: Service area analysis. Available from: http://desktop.arcgis.com/en/arcmap/latest/ extensions /network-analyst/service-area.htm\# Accessed: November 10, 2018.

ESRI, 2018b. ArcGIS for desktop: OD cost matrix analysis. Available from: http://desktop.arcgis.com/en/arcmap/ latest/extensions/network-analyst/od-cost-matrix.htm Accessed: November 10, 2018.

Ford A, Barr S, Dawson R, James P, 2015. Transport accessibility analysis using GIS: assessing sustainable transport in London. ISPRS Int J Geo-Inf 4:124-49.

Granger CB, Alexander JH, McMurray JJ, Lopes RD, Hylek EM, Hanna M, Al-Khalidi HR, Ansell J, Atar D, Avezum A, Bahit MC, Diaz R, Easton JD, Ezekowitz JA, Flaker G, Garcia D, Geraldes M, Gersh BJ, Golitsyn S, Goto S, Hermosillo AG, Hohnloser SH, Horowitz J, Mohan P, Jansky P, Lewis BS, Lopez-Sendon JL, Pais P, Parkhomenko A, Verheugt FW, Zhu J, Wallentin L, 2011. Apixaban versus warfarin in patients with atrial fibrillation. N Engl J Med 365:981-92.

Guagliardo MF, 2004. Spatial accessibility of primary care: concepts, methods and challenges. Int J Health Geogr 3:3.

Hallinen T, Soini E, Asseburg C, Kuosmanen P, Laakkonen A, 2014. Warfarin treatment among Finnish patients with atrial fibrillation: retrospective registry study based on primary healthcare data. BMJ Open 4:e004071.

Hammersley D, Signy M, 2017. Navigating the choice of oral anticoagulation therapy for atrial fibrillation in the NOAC era. Ther Adv Chronic Dis 8:165-76.

Hinojar R, Jiménez-Natcher JJ, Fernández-Golfín C, Zamorano JL, 2015. New oral anticoagulants: a practical guide for physicians. Eur Heart J Cardiovasc Pharmacother 1:134-45.

Hwang JM, Clemente J, Sharma KP, Taylor TN, Garwood CL, 2011. Transportation cost of anticoagulation clinic visits in an urban setting. J Manag Care Pharm 17:635.

Johannesson M, Borgquist L, Jonsson B, 1991. The costs of treating hypertension in Sweden. Scand J Prim Health 9:155-60.

Jowett S, Bryan S, Mahé I, Brieger D, Carlsson J, Kartman B, Nevinson M, 2008. A multinational investigation of time and traveling costs in attending anticoagulation clinics. Value Health 11:207-12.

Krijthe BP, Kunst A, Benjamin EJ, Lip GY, Franco OH, Hofman A, Witteman JC, Stricker BH, Heeringa J, 2013. Projections on the number of individuals with atrial fibrillation in the European Union, from 2000 to 2060. Eur Heart J 34:2746-51.

Leminen A, Tykkyläinen M, Laatikainen T, 2018. Self-monitoring induced savings on type 2 diabetes patients' travel and healthcare costs. Int J Med Inform 115:120-7.

Marcolino MS, Polanczyk CA, Bovendorp AC, Marques NS, Silva LA, Turquia CP, Ribeiro AL, 2016. Economic evaluation of the new oral anticoagulants for the prevention of thromboembolic events: a cost-minimization analysis. Sao Paulo Med J 134:322-9.

Parry D, Bryan S, Gee K, Murray E, Fitzmaurice D, 2001. Patient costs in anticoagulation management: a comparison of primary and secondary care. Brit J Gen Pract 51:972-6.

Patel MR, Mahaffey KW, Garg J, Pan G, Singer DE, Hacke W,
Breithardt G, Halperin JL, Hankey GJ, Piccini JP, Becker RC, Nessel CC, Paolini JF, Berkowitz SD, Fox KA, Califf RM, 2011. Rivaroxaban versus warfarin in nonvalvular atrial fibrillation. N Engl J Med 365:883-891.

Rodrigue J, Comtois C, Slack B, 2009. The geography of transport systems. Routledge, New York, USA.

Salata BM, Hutton DW, Levine DA, Froehlich JB, Barnes GD, 2016. Cost-effectiveness of dabigatran (150 mg twice daily) and warfarin in patients $\geq 65$ years with nonvalvular atrial fibrillation. Am J Cardiol 117:54-60.

Salonen M, Toivonen T, 2013. Modelling travel time in urban networks: comparable measures for private car and public transport. J Transp Geogr 31:143-53.

Schulman S, Anderson DR, Bungard TJ, Jaeger T, Kahn SR, Wells P, Wilson SJ, 2010. Direct and indirect costs of management of long-term warfarin therapy in Canada. J Thromb Haemost 8:2192-200.

Silingardi M, 2013. New anticoagulant drugs versus warfarin in atrial fibrillation: economic evaluation and cost-effectiveness analysis. Ital J Med 7:65-70.

Smith D, 1981. Industrial location. 2nd ed. Wiley, London, UK.

Social Insurance Institution of Finland, 2019. Transport by taxi. Available from: https://www.kela.fi/web/en/transport-by-taxi Accessed: January 22, 2019.

Statistics Finland, 2017. Population structure. Population by sex and area 31.12.2017 and increase of population. Available from: http://pxnet2.stat.fi/PXWeb/pxweb/en/Stat Fin/StatFin __vrm_vaerak/ Accessed: July 27, 2018.

Statistics Finland, 2019. PAAVO - Open data by postal code area. Available from: http://www.stat.fi/org/avoindata/paikkatietoaineistot/paavo_en.html Accessed: January 15, 2019.

Tenkanen H, Saarsalmi P, Järv O, Salonen M, Toivonen T, 2016. Health research needs more comprehensive accessibility measures: integrating time and transport modes from open data. Int J Health Geogr 15:23.

Testa S, Paoletti O, Zimmermann A, Bassi L, Zambelli S, Cancellieri E, 2012. The role of anticoagulation clinics in the era of new oral anticoagulants. Thrombosis 2012:835356.

The Finnish Medical Society Duodecim, 2018. Current care guidelines: atrial fibrillation abstract. Working group set up by the Finnish Medical Society Duodecim and the Finnish Cardiac Society. The Finnish Medical Society Duodecim, Helsinki, Finland. Available from: http://www.kaypahoito.fi/web/kh/ suositukset/suositus?id=hoi50036 Accessed: November 24, 2018.

Verhoef TI, Orlewska WK, Hasrat F, Boer A, Maitland-van der Zee $\mathrm{AH}, 2014$. Cost effectiveness of new oral anticoagulants for stroke prevention in patients with atrial fibrillation in two different European healthcare settings. Am J Cardiovasc Drugs 14:451-62.

Verhoef TI, Redekop WK, van Schie RM, Bayat S, Daly AK, Geitona M, Haschke-Becher E, Hughes DA, Kamali F, Levin LÅ, Manolopoulos VG, Pirmohamed M, Siebert U, Stingl JC, Wadelius M, de Boer A, Maitland-van der Zee AH, 2012. Costeffectiveness of pharmacogenetics in anticoagulation: international differences in healthcare systems and costs. Pharmacogenomics 13:1405-17.

Zoni-Berisso M, Lercari F, Carazza T, Domenicucci S, 2014. Epidemiology of atrial fibrillation: European perspective. Clin Epidemiol 6:213-20. 